\title{
O PROGRAMA BOLSA FAMÍLIA E O MERCADO DE TRABALHO INFORMAL: UMA ANÁLISE DE IMPACTO DA AÇÃO BRASIL CARINHOSO
}

\author{
Luísa de Azevedo Nazareno *
}

\begin{abstract}
Resumo
O presente artigo objetiva verificar a existência de impactos da ação Brasil Carinhoso em uma eventual escolha pela informalidade por parte dos seus beneficiários. Parte-se de grupos de controle e tratamento, criados a partir das PNADs 2011 e 2012, compostos por indivíduos ocupados elegíveis ou potencialmente elegíveis ao benefício. O principal resultado encontrado aponta para uma relação significativa e negativa entre o recebimento do benefício Brasil Carinhoso e a escolha pela informalidade. Entre as possíveis explicações para tanto, levanta-se a hipótese de que o benefício alivie restrições de liquidez na busca por empregos. Testes de robustez, contudo, não sustentam a conclusão.
\end{abstract}

Palavras-chave: Bolsa Família, Brasil Carinhoso, Informalidade, Escolha ocupacional.

\begin{abstract}
This paper studied the existence of impacts of the Brazilian cash transfer Brasil Carinhoso in the occupational choice of its beneficiaries, mainly their possible preference for informality. In order to test that, we use treatment and control groups created from PNADs 2011 and 2012, consisting of employed people eligible or potentially eligible for the benefit. The main conclusion points to a significant and negative relationship between the receipt of Brasil Carinhoso benefit and the choice for informality. A possible explanation for that relies in the hypothesis that the benefit might ease liquidity constraints in the search for jobs. Robustness tests, however, do not sustain such conclusion.
\end{abstract}

Keywords: Bolsa Família, Brasil Carinhoso, Informality, Occupational choice.

JEL classification: H00, H24, J24

DOI: http://dx.doi .org/10.11606/1413-8050/ea 153891

\footnotetext{
*Universidade de Brasilia. E-mail: luisa.nazareno@gmail.com.
} 


\section{Introdução}

Em 2014, o Programa Bolsa Família (PBF) completou 10 anos de existência no Brasil. O PBF insere-se na categoria de programas de transferência condicionada de renda que, a partir do início do século XXI, passa a emergir nos países da América Latina como estratégia de intervenção estatal contra a pobreza, a exemplo do programa Oportunidades (ou Progresa) no México e do Chile Solidario no Chile.

Ao longo de sua década de existência, foram realizados inúmeros estudos relativos aos seus impactos diretos e indiretos. Como resultado, algumas questões encontraram relativo consenso na literatura - tais como a eficácia do programa em seu principal objetivo de redução da pobreza, ao passo em que novos horizontes de pesquisa permanecem em aberto.

Estudos acerca dos impactos do PBF no mercado de trabalho surgiram inicialmente com o objetivo de verificar a existência do denominado "efeito preguiça" entre os beneficiários, isto é, um impacto negativo em suas ofertas de trabalho decorrentes do benefício recebido. De maneira geral, os resultados encontrados apontam para a inexistência ou não significância do "efeito preguiça"(Oliveira \& Soares 2013, Barbosa \& Corseuil 2013, Foguel \& Barros 2010).

Emerge, então, uma segunda preocupação referente aos impactos do PBF na composição da força de trabalho, em especial, na composição do mercado de trabalho em setores formal e informal. À luz dos debates acerca informalidade e desenvolvimento, essas questões ganham especial relevância, contudo no Brasil ainda carecem referências sobre o tema (Barbosa \& Corseuil 2013).

Buscando prover novas evidências empíricas sobre a questão, o objetivo do presente trabalho é testar a relação entre o recebimento de benefícios e uma eventual escolha por uma ocupação informal, a partir de uma das fases de expansão do Bolsa Família, conhecida como ação Brasil Carinhoso. A ação Brasil Carinhoso, que passou a ser paga em junho de 2012, foi inicialmente destinada a todas as famílias com crianças de até seis anos de idade que, mesmo após o recebimento do benefício do PBF, continuavam abaixo da linha de extrema pobreza.

Para mensurar os efeitos da ação Brasil Carinhoso na escolha ocupacional, foi criado um grupo de tratamento a partir da PNAD 2012, constituído pelos beneficiários efetivos do programa ocupados na semana da pesquisa, e um grupo de controle a partir da PNAD 2011, semelhante ao primeiro, porém não beneficiário (dada a inexistência do programa nesse ano). A partir dos grupos, por meio do método de mínimos quadrados ordinários, foi testada a relação entre o novo benefício e uma eventual escolha ou preferência pela informalidade.

O principal resultado encontrado foi uma relação significativa e negativa entre o recebimento do benefício Brasil Carinhoso e uma escolha pela informalidade. Tal resultado poderia se sustentar, por exemplo, na hipótese de que o benefício aliviaria restrições de liquidez na busca por melhores empregos. Testes de robustez realizados, contudo, não confirmam a conclusão.

\section{A ação Brasil Carinhoso}

A despeito das melhoras promovidas pelo Bolsa Família nos níveis de renda e bem-estar das famílias beneficiárias, foi identificada uma persistência da 
condição de extrema pobreza em alguns grupos, notadamente entre famílias com crianças de até seis anos de idade. Visando melhorar as condições de vida dessas famílias e romper com a pobreza extrema na primeira infância, foi anunciada, em 13 de maio de 2012, dia das mães, a criação do chamado Benefício para Superação da Extrema Pobreza na Primeira Infância no âmbito do Programa Brasil sem Miséria, ou simplesmente, Ação Brasil Carinhoso.

O Brasil Carinhoso foi anunciado, inicialmente, como um benefício variável que completaria a renda domiciliar per capita de famílias com crianças de até seis anos e que, mesmo após o recebimento do benefício, ainda permaneciam com renda domiciliar per capita igual ou inferior a $\mathrm{R} \$ 70,00$ (linha de extrema pobreza naquele ano). O valor do benefício seria calculado como o hiato entre a renda domiciliar per capita da família e a linha de extrema pobreza.

A expectativa do Governo Federal era de que a ação Brasil Carinhoso retirasse ao menos 2 milhões de famílias da faixa de extrema pobreza. (Ministério do Desenvolvimento Social e Combate à Fome 2014). Adicionalmente, Osorio \& Souza (2012) calcularam que o programa teria condições de reduzir a extrema pobreza infantil a $0,6 \%$.

Regulamentado pelo Decreto $\mathrm{n}^{\circ} 7.758$ de 15 de julho de 2012, o benefício começou a ser pago automaticamente em junho de 2012, por meio do cartão do Bolsa Família, a todas as famílias que atendiam aos requisitos, sem necessidade de cadastramento. Em novembro desse mesmo ano, contudo, a faixa etária foi expandida também para famílias com crianças de 7 a 15, que passaram a receber o benefício em 10 de dezembro de 2012. Com isso, o Brasil Carinhoso vigorou, em seu formato original, por um curto espaço de tempo. No entanto, como os questionários da PNAD 2012 foram colhidos antes da expansão do benefício, fez-se possível verificar seus impactos iniciais.

\section{Transferências Condicionadas de Renda e o Mercado de Trabalho}

A literatura com relação aos impactos de transferências de renda no mercado de trabalho tem sido objeto tanto da economia do trabalho quanto do desenvolvimento econômico. $\mathrm{O}$ foco da economia do trabalho tem sido a estimação dos efeitos de transferências na composição da força de trabalho, número de horas trabalhadas e impactos nos ciclos econômicos. Por sua vez, a preocupação da literatura do desenvolvimento tem sido verificar se as transferências incentivam adultos a permanecerem fora da força de trabalho, gerando uma armadilha da pobreza, ou ainda a preferirem empregos informais (Ribas \& Soares 2011).

Ao menos dois tipos de análise de impactos de programas de transferência condicionada de renda são recorrentes na literatura. De um lado, existe uma abordagem que trata de efeitos dos programas nas margens intensiva (número de horas de trabalho ofertadas) e extensiva (participação ou não no mercado de trabalho) (Saez 2002, Meyer 2002). Nesse tipo de análise, que pode também ser utilizada para estudos de transferências não condicionadas de renda, a identificação de em que margem há um efeito significativo tem sido considerada importante para aperfeiçoar o desenho dos programas.

De outro lado, alguns estudiosos têm utilizado uma abordagem de efeitos renda e substituição (Skoufias \& Di Maro 2006, Alzua et al. 2010, Barbosa \& 
Corseuil 2013). Em termos teóricos, de acordo com um modelo estático em que um indivíduo escolhe entre trabalho e lazer, a transferência do PBF representaria um efeito renda em sua restrição orçamentária. Intuitivamente, o aumento da renda faria com que o indivíduo optasse por usufruir de uma maior quantidade de lazer, resultando em um impacto negativo em sua oferta de trabalho. No Brasil, o possível efeito de desincentivo ao trabalho por parte dos beneficiários ficou conhecido na literatura como "efeito preguiça" e tem sido provado inexistente ou não estatisticamente significativo por estudos empíricos. (Oliveira \& Soares 2013, Foguel \& Barros 2010).

Ribas \& Soares (2011, pp. 2-3) argumentam que diversos outros possíveis efeitos diretos e indiretos de programas de renda podem recair sobre a oferta de trabalho das famílias. Primeiramente, se lazer é um bem normal, o aumento da renda pode provocar uma redução na quantidade ofertada de trabalho das famílias, conforme mencionado. Além disso, sendo o lazer um bem normal ou não, é possível que algumas famílias prefiram reduzir ganhos incertos (provenientes do trabalho), com o objetivo de auferir um maior ganho certo (proveniente das transferências). Em segundo lugar, é possível que adultos sejam incentivados a ocupar trabalhos informais, de modo a impedir a identificação de sua renda real pelo governo, permanecendo, assim, elegíveis ao benefício. Por outro lado, em terceiro lugar, na presença de restrições de crédito, a concessão do benefício pode ser vista como uma oportunidade para a realização de investimentos pelas famílias, impactando o trabalho positivamente. Em quarto lugar, a obrigatoriedade de as crianças frequentarem a escola permite que as mães possam ingressar no mercado de trabalho. Ademais, as condicionalidades podem provocar uma redução no orçamento doméstico na medida em que reduzem ou impedem o trabalho infantil. Com isso, é possível que seja necessário aumentar a oferta de trabalho dos adultos para compensar a perda. Por fim, transferências também podem afetar indiretamente o salário de equilíbrio das economias, tanto por provocarem um aumento na demanda por produtos quando por afetarem a oferta de trabalho.

Além dos efeitos mencionados, há uma linha de estudos que têm buscado compreender o papel das transferências nas restrições de liquidez e seguro dos beneficiários. Nesse caso, analisa-se a possibilidade de o choque provocado pelas transferências cumprir algum papel redutor nas restrições de seguro (uma vez que garantiria uma renda mínima às famílias, permitindo uma menor aversão ao risco) e de liquidez (já que poderia viabilizar empréstimos entre amigos e familiares, criando uma linha informal de crédito que facilitaria o financiamento de pequenos empreendimentos por parte dos beneficiários). ${ }^{1}$

Outra questão que tem se tornado relevante na literatura relaciona-se aos impactos de transferências condicionadas de renda na composição da força de trabalho, em especial, na composição do mercado de trabalho em setores formal e informal. Em outras palavras, questiona-se a possibilidade de que indivíduos optem por permanecerem em postos informais de trabalho, de modo a continuarem elegíveis ao recebimento do benefício. Acerca dessa possibilidade e considerando-se os objetivos do presente artigo, apresentam-se, a partir de agora, em alguns estudos recentes que se ocuparam da relação Bolsa Família - mercado de trabalho.

\footnotetext{
${ }^{1}$ Bianchi \& Bobba (2013), Gertler (2012), Banerjee \& Newman (1993).
} 
Com relação ao tema, Marinho \& Mendes (2013) analisaram, a partir da Pesquisa Nacional de Amostra Domiciliar (PNAD) 2006, os impactos do PBF sobre a oferta de trabalho formal e informal dos chefes de família no Brasil, bem como seus efeitos sobre as decisões dos indivíduos de entrarem ou não no mercado de trabalho. Os resultados encontrados apontam para um efeito marginal positivo do PBF para trabalhos informais ou desemprego, ao passo que o emprego formal é afetado negativamente. Ademais, o número de horas de trabalho ofertado pelos trabalhadores tende a ser menor conforme o aumento do benefício.

De maneira semelhante, Teixeira (2010) analisa o impacto do "choque de renda" decorrente do PBF na oferta de trabalho dos beneficiários, medido pela probabilidade de trabalho e pelo número de horas semanais trabalhadas por homens e mulheres. O estudo conclui que não existe impacto significativo, contudo, diferenças importantes são observadas na elasticidade de homens e mulheres ao choque de renda. De igual maneira, ao estimar o impacto de programas de transferência de renda na oferta de trabalho de homens e mulheres adultos, Foguel \& Barros (2010) não encontram significância estatística para mulheres, ao passo que para homens existe um impacto, porém de baixa magnitude.

Barbosa \& Corseuil (2013), por sua vez, também investigam o impacto do PBF na composição do mercado de trabalho brasileiro, desenvolvendo uma regressão com descontinuidade difusa a partir de uma amostra reduzida da PNAD. Aqui também resultados não apontam para efeitos significativos do PBF na escolha ocupacional dos chefes de família.

Em contraposição, o estudo de Ribas \& Soares (2011) aponta para um resultado ligeiramente distinto dos mencionados previamente. Segundo os autores, os efeitos no mercado de trabalho podem diferir quando os programas passam de áreas rurais isoladas para grandes cidades, nas quais seus beneficiários são amplamente informados sobre as regras de elegibilidade. Após a realização de testes econométricos, os autores concluem que em áreas rurais o programa resulta em efeitos positivos na participação do chefe do domicílio na força de trabalho, ao passo que em áreas urbanas se nota uma redução de sua participação no setor formal. Dessa forma, não é possível rejeitar a hipótese de que o PBF causaria dependência para o caso de cidades grandes.

Frente à variedade de resultados encontrados, torna-se claro que ainda não existe uma resposta conclusiva para a relação entre PBF e uma eventual opção pela informalidade por parte dos beneficiários. Todavia, em sendo a informalidade um fenômeno com consequências danosas para a sociedade e para o desenvolvimento, faz-se necessário dedicar algumas linhas para a melhor compreensão do tema.

Com relação aos possíveis efeitos de transferências condicionadas de renda sobre a informalidade não é possível estabelecer a priori qual seria sua direção ou intensidade, uma vez que a literatura disponível abarca possibilidades tanto positivas quanto negativas.

Dentre os argumentos teóricos que explicariam um aumento da informalidade devido às transferências pode ser incluída, por exemplo, a questão de que a renda extra garantiria às famílias um mínimo necessário, de forma a permitir que as mães preferissem uma ocupação informal com maior flexibilidade e, portanto, maior facilidade na compatibilização do trabalho com afazeres domésticos e cuidados com os filhos. Tal argumentação está presente nos trabalhos de Marinho \& Mendes (2013) e Teixeira (2010). Ademais, 
pode-se argumentar também que as transferências representariam um alivio às restrições de liquidez e de fontes de financiamento que permitiram a alguns trabalhadores iniciar empreendimentos próprios, mesmo que inicialmente na informalidade, a exemplo das discussões de Bianchi \& Bobba (2013) e Gertler (2012). Por fim, pode-se argumentar que, para garantir o recebimento dos benefícios, alguns trabalhadores poderiam preferir a ocupação de postos informais, que facilitariam a omissão de seus ganhos salariais reais.

Por outro lado, sobre possíveis efeitos negativos na informalidade, pode-se argumentar que transferências representariam uma redução nas restrições de liquidez na busca por emprego por parte dos indivíduos que, ao receberem o benefício, poderiam, por exemplo, ter acesso a novas fontes de anúncio de empregos formais, bem como estar mais bem preparados para um entrevista, seja estando aptos a comprar roupas adequadas, seja tendo condições de utilizar transportes mais eficientes para seu deslocamento. Do lado das restrições de seguro, pode-se esperar, também, que, estando minimamente assegurados pelo benefício, os chefes de domicílio poderiam se arriscar mais na busca por empregos formais, partindo-se do entendimento de que tais empregos seriam melhores ao fornecer maiores garantias ao trabalhador.

Nota-se que, partindo do mesmo argumento de restrição de seguros na busca por empregos, pode-se tanto argumentar por um aumento na busca de postos informais (com a transferência representando uma garantia de renda fixa para os beneficiários, que poderiam por razões diversas preferir postos informais) quanto por um aumento na busca por ocupações formais (uma vez que o seguro permitiria aos beneficiários abandonar parcialmente as horas destinadas ao trabalho informal para dedicar-se mais à busca por postos formais, considerados melhores).

Portanto, ressalte-se que impactos positivos e negativos sobre a informalidade poderiam ser os mais diversos e as possíveis explicações teóricas não se restringem a presente discussão. Assim é perfeitamente possível que cada um dos efeitos seja contemplado nas decisões ocupacionais dos beneficiários e, portanto, apenas empiricamente será possível verificar qual prevalece.

\section{Metodologia}

Para a consecução do presente artigo, foram utilizados dados da Pesquisa Nacional por Amostra de Domicílios (PNAD) 2011 e 2012, divulgada anualmente pelo Instituto Brasileiro de Geografia e Estatística (IBGE). Os dados de ambas as pesquisas (arquivos "pessoas") foram reunidos em uma única base de dados, a partir da qual, por meio da metodologia desenvolvida por Souza \& Osorio (2011) foram identificados e mantidos apenas os chefes de família beneficiários do PBF e, potencialmente ${ }^{2}$, beneficiários do Brasil Carinhoso. Passou-se, portanto, a trabalhar com uma base composta por informações de indivíduos distintos coletadas nos anos 2011 e 2012.

A partir dos dados, foram criadas duas subamostras ('PBF' e 'Carinhoso') compostas, respectivamente, por indivíduos beneficiários do PBF nos anos 2011 e 2012 e por indivíduos que se enquadram nos requisitos estabelecidos

\footnotetext{
${ }^{2}$ Potencialmente beneficiários porque beneficiários efetivos somente poderiam existir em 2012. Em 2011 o que se pôde identificar foram pessoas que se enquadrariam como beneficiárias do Brasil Carinhoso caso este já estivesse em vigor.
} 
inicialmente para o recebimento do Brasil Carinhoso nesses anos ${ }^{3}$. Note-se que, como o benefício passou a ser pago no ano de 2012, os indivíduos da amostra Carinhoso entrevistados em 2011 constituem um grupo que efetivamente não recebeu a transferência (dada a impossibilidade temporal), mas que possui características muito semelhantes ao grupo de indivíduos que em 2012 efetivamente foi beneficiário. Têm-se, a partir da amostra Carinhoso, os grupos de controle (2011) e tratamento (2011) que permitiram testar a relação entre o novo benefício e a escolha ocupacional.

O método de mínimos quadrados ordinários foi utilizado para testar a hipótese de que, na amostra Carinhoso, haveria alguma diferença na quantidade de ocupações informais entre os chefes de família entre 2011 e 2012. Como o objetivo central relaciona-se à ocupação dos chefes de família, foram excluídos todos aqueles que não se encontravam ocupados no momento em que responderam às pesquisas, de forma que os resultados encontrados são condicionais ao fato de indivíduos estarem ocupados, nada podendo inferir acerca dos impactos na desocupação.

Definiu-se a proxy de informalidade a partir da categoria auto declarada como "conta própria" nos questionários das PNADs. Por sua vez, a variável independente de interesse na amostra restrita de beneficiários do Brasil Carinhoso foi "carinhoso", definida como variável binária igual a zero para o ano 2011 e um para 2012. Como controle, foram utilizadas variáveis essencialmente demográficas, a saber: mulher, negro, rural, idade, tamanho da família, número de anos de estudo, renda familiar per capita, número de filhos que moram no domicílio, número de horas dedicadas ao trabalho doméstico e regiões geográficas. O modelo foi testado tanto para a amostra Carinhoso quanto para a amostra PBF a título de comparação. Embora análises do tipo antes e depois na avaliação de políticas públicas sejam passíveis de críticas por não ser possível identificar com segurança se mudanças ocorridas advém diretamente da política ou de outras causas, a comparação dos efeitos nas amostras PBF e Carinhoso contribui para validar o modelo escolhido, na medida em que, caso a mudança de ano seja significativa apenas na amostra Carinhoso e não na PBF, é razoável supor que a significância vincule-se ao início da política.

Finalmente foram realizados testes de robustez e verificada a existência de efeitos heterogêneos. No primeiro caso, a proxy "conta-própria" foi substituída por novas proxies de informalidade (não possuir previdência e não possuir carteira de trabalho assinada), bem como foram testado os efeitos de "carinhoso" sobre o número de horas de trabalho ofertadas. No segundo caso, foram verificados a existência de coeficientes significativos de "carinhoso" em interação com as variáveis "mulher", "rural", "negro" e com cada uma das variáveis dummies de regiões. Cumpre notar que, em todas as estimativas realizadas a partir da amostra, os dados foram ajustados pela categoria referente ao peso amostral (V4729).

\footnotetext{
${ }^{3}$ Lembrando que, em virtude do próprio desenho da ação Brasil Carinhoso, o grupo de beneficiários constitui-se em uma parcela dos beneficiários do Bolsa Família. Assim, a amostra Carinhoso é, também, uma subamostra de PBF.
} 


\section{Resultados}

\subsection{Análise de regressão}

A seguir, testa-se a existência de impactos da ação Brasil Carinhoso em uma eventual escolha pela informalidade por parte dos chefes de domicílio de famílias beneficiárias. Para tanto, são utilizadas comparativamente as duas amostras apresentadas previamente, de forma que os resultados são condicionais a condição de ocupado.

Para testar a hipótese de efeitos do recebimento do benefício Brasil Carinhoso em uma eventual escolha ocupacional pela informalidade, utilizou-se o método de mínimos quadrados ordinários. Como proxy para informalidade utilizou-se a categoria ocupacional conta-própria. Embora existam alguns inconvenientes com tal definição, a suposição é razoável uma vez que no setor informal predominam trabalhadores conta-própria (Barbosa \& Corseuil 2013). Por sua vez, a variável independente de interesse na amostra restrita de beneficiários do Brasil Carinhoso é "carinhoso", definida como variável binária igual a zero para o ano 2011 e um para 2012. Finalmente, como controles, foram utilizadas variáveis essencialmente demográficas.

Os resultados mostram um coeficiente significativo e negativo para o benefício Brasil Carinhoso, indicando um impacto redutor, ainda que pequeno, da informalidade. Em outras palavras, ao iniciar o pagamento do benefício Brasil Carinhoso teria havido uma redução nas ocupações informais dos beneficiários. Uma das possíveis interpretações de tal resultado seria a redução nas restrições de liquidez na busca por empregos por parte dos indivíduos, que estariam em melhores condições de buscar ocupações formais. Assim, ao estarem minimamente assegurados pelo benefício, os chefes de domicílio poderiam se arriscar e deixar um pouco de lado a ocupação "conta-própria" para dedicar-se um pouco mais à busca por empregos formais.

$\mathrm{O}$ procedimento foi repetido para a amostra de beneficiários do Bolsa Família, com vistas a identificar alguma possível descontinuidade entre os anos, que ajude a explicar o resultado obtido na amostra menor. Sem perda de generalidade, a variável independente de interesse foi renomeada como ano2012, uma vez que careceria de sentido utilizar o recebimento ou não do benefício Brasil Carinhoso nessa amostra maior, não elegível ao benefício. Os resultados encontrados são apresentados na tabela 1 .

Nesse caso, o ano deixa de ser significativo para explicar a opção pela categoria conta-própria, ao mesmo tempo em que algumas variáveis de controle, tais como sexo, raça e anos de estudo, ganham importância estatística. Com isso, é reforçado o argumento de que o benefício Brasil Carinhoso seria efetivamente significativo, e não um mero instrumento representativo da mudança de ano. Ademais, destaca-se que, mesmo com o aumento da amostra a capacidade explicativa do modelo para a amostra PBF torna-se ainda menor, conforme indica a redução do $R^{2}$.

Com isso, os modelos estimados indicam que houve um impacto, ainda que pequeno, da ação Brasil Carinhoso na redução da informalidade na amostra Carinhoso. O mesmo não ocorre ao se analisar o grupo beneficiário do Bolsa Família como um todo, indicando ausência de descontinuidade entre os anos 2011 e 2012.

Tais resultados, contudo, devem ser vistos com cautela tanto pelos baixos coeficientes dos modelos, quanto pelo fato de captarem efeitos de curtíssimo 
prazo, uma vez que na data da realização da PNAD 2012, o programa estava em vigor há poucos meses. Com isso, para validar os resultados obtidos, devem ser realizados ao menos alguns testes de robustez e heterogeneidade.

Tabela 1: Regressões lineares múltiplas - amostras Carinhoso e PBF

\begin{tabular}{lcc}
\hline & Amostra Carinhoso & Amostra PBF \\
\hline Carinhoso ou ano 2012* & $-0,1662$ & 0,0073 \\
& $(0,0488)$ & $(0,0068)$ \\
Constante & 0,118 & 0,1637 \\
& $(0,1978)$ & $(0,0236)$ \\
Controles & Sim & Sim \\
N & 366 & 17111 \\
$R^{2}$ & 0,194 & 0,0865 \\
\hline
\end{tabular}

Amostra Carinhoso: composta por chefes de famílias beneficiárias do Brasil Carinhoso em 2012 e famílias que atenderiam aos critérios de elegibilidade em 2011.

Amostra PBF: composta por chefes de famílias beneficiárias do PBF em 2011 e 2012.

Erro padrão entre parênteses

*Para a amostra carinhoso, a variável foi denominada carinhoso, ao passo que para a amostra PBF a variável foi denominada ano2012.

** Controles utilizados: mulher, negro, rural, idade, tamanho da família, anos de estudo, renda familiar per capita, filhos que moram no domicílio, horas de trabalho doméstico, e grandes regiões geográficas.

\subsection{Efeitos heterogêneos}

No tópico anterior, encontrou-se um efeito significativo para o benefício Brasil Carinhoso na amostra Carinhoso. Nesta seção, testa-se a existência de efeitos heterogêneos em algumas dessas variáveis quando há interação com a variável explicativa "carinhoso".

Para tanto, são criados termos de interação para as variáveis "mulher", "negro", "rural", bem como para todas as regiões, exceto Norte (região basal) e realizadas quatro regressões por mínimos quadrados ordinários. A tabela 2 fornece os coeficientes e erros padrões obtidos no experimento. 
Tabela 2: Efeitos heterogêneos - amostra Carinhoso

\begin{tabular}{|c|c|c|c|c|}
\hline & $\begin{array}{l}\text { T1: interação } \\
\text { mulher }{ }^{*} \text { carinhoso }\end{array}$ & $\begin{array}{c}\text { T2: interação } \\
\text { negro*carinhoso }\end{array}$ & $\begin{array}{l}\text { T3: interação } \\
\text { rural }^{*} \text { carinhoso }\end{array}$ & $\begin{array}{l}\text { T4: interação } \\
\text { regiões }{ }^{*} \text { carinhoso }\end{array}$ \\
\hline Carinhoso & $\begin{array}{c}-0,2021 \\
(0,0600)\end{array}$ & $\begin{array}{c}-0,2173 \\
(0,1132)\end{array}$ & $\begin{array}{c}-0,1712 \\
(0,0824)\end{array}$ & $\begin{array}{c}-0,1651 \\
(0,1424)\end{array}$ \\
\hline Mulher & $\begin{array}{c}-0,0637 \\
(0,1197)\end{array}$ & & & \\
\hline Mulher ${ }^{*}$ carinhoso & $\begin{array}{l}0,1045 \\
(0,1017)\end{array}$ & & & \\
\hline Negro & & $\begin{array}{c}-0,1028 \\
(0,0825)\end{array}$ & & \\
\hline Negro*carinhoso & & $\begin{array}{l}0,0631 \\
(0,1262)\end{array}$ & & \\
\hline Rural & & & $\begin{array}{c}-0,0362 \\
(0,0667)\end{array}$ & \\
\hline Rural $^{*}$ carinhoso & & & $\begin{array}{l}0,0077 \\
(0,1020)\end{array}$ & \\
\hline Centro-oeste & & & & $\begin{array}{c}-0,8383 \\
(0,5516)\end{array}$ \\
\hline $\begin{array}{l}\text { Centro- } \\
\text { oeste }^{*} \text { carinhoso }\end{array}$ & & & & $\begin{array}{l}0,8647 \\
(0,7819)\end{array}$ \\
\hline Nordeste & & & & $\begin{array}{c}-0,1228 \\
(0,0879)\end{array}$ \\
\hline Nordeste $^{*}$ carinhosc & & & & $\begin{array}{c}-0,0074 \\
(0,1522)\end{array}$ \\
\hline Sudeste & & & & $\begin{array}{l}0,2248 \\
(0,1774)\end{array}$ \\
\hline Sudeste $^{*}$ carinhoso & & & & $\begin{array}{l}0,0208 \\
(0,2931)\end{array}$ \\
\hline Sul & & & & $\begin{array}{l}0,0431 \\
(0,1906)\end{array}$ \\
\hline Sul $^{*}$ carinhoso & & & & $\begin{array}{l}-0,016 \\
(0,3522)\end{array}$ \\
\hline Constante & $\begin{array}{l}0,1284 \\
(0,1981)\end{array}$ & $\begin{array}{l}0,1526 \\
(0,2098)\end{array}$ & $\begin{array}{l}0,1202 \\
(0,2003)\end{array}$ & $\begin{array}{l}0,1086 \\
(0,2029)\end{array}$ \\
\hline $\mathrm{N}$ & 366 & 366 & 366 & 366 \\
\hline $\mathrm{R}^{2}$ & 0,1964 & 0,1946 & 0,1940 & 0,1970 \\
\hline
\end{tabular}

Nota: Erro-padrão entre parênteses.

Como os coeficientes das variáveis de interação não são significativos, concluise que não existem efeitos heterogêneos entre os grupos por sexo, raça, ou região. Contudo, nota-se que, exceto pela inclusão da variável de interação mulher * carinhoso e rural *carinhoso, em todas as demais regressões, o coeficiente de "carinhoso" perde sua significância estatística. De certa forma, tal fato enfraquece o resultado encontrado anteriormente, reforçando a necessidade de que sejam realizados alguns testes de robustez.

\subsection{Testes de robustez}

Embora tenha sido encontrado um coeficiente significativo para o benefício Brasil Carinhoso na amostra específica na seção anterior, faz-se necessário realizar novos testes para validar a conclusão. Para tanto, nesta seção são realizados alguns testes para verificar quão robustas são as conclusões apresentadas previamente.

Como a variável dependente conta-própria foi utilizada como proxy de informalidade, é possível que essa escolha gere algum viés nos resultados, já que a variável poderia ser, por exemplo, uma maneira questionável de se captar o fenômeno informalidade. Para verificar a hipótese, são testadas duas novas proxies para informalidade: não ser contribuinte da previdência social e não ser empregado com carteira de trabalho assinada. Além disso, verificam- 
se, também, possíveis impactos do programa Brasil Carinhoso no número de horas trabalhadas por semana (variável criada a partir do somatório de horas trabalhadas em todos os possíveis trabalhos remunerados dos indivíduos). Com isso, torna-se possível verificar se o efeito significativo permanece ou desaparece com a troca da variável explicada.

Com relação às novas proxies para informalidade, deve-se ter em conta que essas variáveis também sofrem limitações: embora seja intuitivo que trabalhadores contribuintes da previdência social e com carteira de trabalho assinada sejam trabalhadores formais, o contrário não é necessariamente verdadeiro, ou seja, não se pode concluir diretamente que não contribuintes da previdência e pessoas sem carteira assinada sejam necessariamente trabalhadores informais. Além disso, como discutido na seção de análise descritiva, existe entre os membros do grupo uma grande quantidade de não respostas nas questões relativas a carteira de trabalho, o que reduz o poder explicativo do modelo. A Tabela 3 apresenta os coeficientes obtidos para as novas regressões realizadas.

Tabela 3: Testes de robustez - amostra Carinhoso

\begin{tabular}{lccc}
\hline & Horas trabalhadas & $\begin{array}{c}\text { Ausência de carteira } \\
\text { de trabalho assinada }\end{array}$ & $\begin{array}{c}\text { Ausência de previdência } \\
\text { social }\end{array}$ \\
\hline Carinhoso & 0,3863 & 0,0029 & $-0,0228$ \\
Constante & $(1,3861)$ & $(0,0042)$ & $(0,0171)$ \\
Controles* & $(5,6163)$ & 1,0063 & 1,0349 \\
$\mathrm{~N}$ & Sim & $(0,0172)$ & $(0,0693)$ \\
$\mathrm{R}^{2}$ & 366 & Sim & 366 \\
\hline Amostra composta por chefes de famílias beneficiárias do Brasil Carinhoso em \\
2012 e famílias que atenderiam aos critérios de elegibilidade em 2011. \\
Erro padrão entre parênteses. \\
* Controles utilizados: mulher, negro, rural, idade, tamanho da família, anos \\
de estudo, renda familiar per capita, filhos que moram no domicílio, horas de \\
trabalho doméstico, e grandes regiões geográficas.
\end{tabular}

Os resultados encontrados mostram que não existe impacto significativo da ação Brasil Carinhoso nem na escolha pela informalidade nem no número de horas dedicadas a trabalho remunerado, o que provê subsídios para que se questione o resultado significativo da variável carinhoso encontrado previamente.

Com isso, não foram encontradas evidências suficientes para supor que exista algum impacto significativo do benefício Brasil Carinhoso na escolha ocupacional pela informalidade por parte das famílias beneficiárias, o que vem sendo corroborado, de certa forma, pelos estudos acerca de PBF e informalidade. Contudo, ao serem analisados os resultados aqui encontrados, deve-se ter em mente a infinidade de limitações impostas a este estudo, tanto decorrentes do breve período de vigência do benefício no ano 2012, como inerentes à técnica econométrica utilizada. O primeiro ponto refere-se essencialmente à dificuldade de se verificar os impactos de um novo benefício em um prazo tão curto: a realização da PNAD 2012 ocorreu pouco mais de um mês após o início do pagamento do Brasil Carinhoso. Já o segundo ponto refere-se às limitações das proxies de informalidade utilizadas para captar o mercado de trabalho informal, ao possível viés de variáveis omitidas presentes nos modelos, bem como a limitação da análise antes e depois, já discutida. 


\section{Conclusões}

O presente artigo constitui contribuição à literatura que investiga a relação entre programas de transferência condicionada de renda e a escolha ocupacional de seus beneficiários. Mostrou-se que, embora muito tenha sido pesquisado acerca de um possível efeito preguiça e de impactos nas margens intensiva e extensiva, os estudos acerca dos impactos na composição da força de trabalho são relativamente recentes.

O principal resultado encontrado foi uma relação significativa e negativa entre o recebimento do benefício Brasil Carinhoso e uma eventual escolha pela ocupacional informal, sinalizando que o recebimento do benefício funcionaria como um desincentivo à informalidade. Como discutido, tal resultado poderia ser explicado, por exemplo, por meio da hipótese de redução nas restrições de liquidez na busca por empregos. No entanto, também foram apresentados algumas razões para questionar tal resultado, como o curto período de ação do programa à época da coleta de dados da PNAD 2012 e os resultados não significativos obtidos ao trocarmos a proxy utilizada para informalidade.

Com isso, o artigo finaliza com um indicativo de que poderia haver uma relação entre transferências de renda e a redução da informalidade. Contudo, como estudos que investigam a relação entre escolha ocupacional e transferências condicionadas de renda são relativamente recentes, fazem-se necessários novos estudos que avaliem tal relação. No caso do resultado aqui encontrado, por exemplo, há espaço para que sejam realizados testes por meio de outras técnicas ou ainda utilizando outras proxies para informalidade.

\section{Agradecimentos}

Agradeço ao Professor Dr. Christian Lehmann, que me apoiou na realização deste trabalho.

\section{Referências Bibliográficas}

Alzua, M. L., Cruces, G. \& Ripani, L. (2010), Welfare programs and labor supply in developing countries. experimental evidence from latin america.

Banerjee, A. V. \& Newman, A. F. (1993), 'Occupational choice and the process of development.', Journal of Political Economy 101(2), 274-298.

Barbosa, A. L. N. H. \& Corseuil, C. H. L. (2013), Bolsa família, escolha ocupacional e informalidade no brasil., in T. Campelo \& M. C. Neri, eds, 'Programa Bolsa Família: uma década de inclusão e cidadania', IPEA, Brasília, pp. $327-$ 339.

Bianchi, M. \& Bobba, M. (2013), 'Liquidity, risk, and occupational choices', The Review of Economic Studies 80(2), 491-511.

Foguel, M. N. \& Barros, R. P. (2010), 'The effects of conditional cash transfer programmes on adult labour supply: an empirical analysis using a timeseries-cross-section sample of brazilian municipalities', Estudos Econômicos $40(2)$. 
Gertler, P. J.; Martinez, S. W. R.-C. M. (2012), 'Investing cash transfers to raise long-term living standards', American Economic Journal: Applied Economics $4(1), 164-192$.

Marinho, E. \& Mendes, S. (2013), 'The impact of government income transfers on the brazilian job market', Estudos econômicos 43(1), 29-50.

Meyer, B. (2002), 'Labor supply at the extensive and intensive margins: The eitc, welfare, and hours worked', American Economic Review 92(2), 373-379.

Ministério do Desenvolvimento Social e Combate à Fome (2014), Bolsa família, Technical report, Brasil.

URL: $h t t p: / / w w w . m d s . g o v . b r / b o l s a f a m i l i a$

Oliveira, L. F. B. \& Soares, S. S. D. (2013), "efeito preguiça” em programas de transferência de renda?, in T. Campello \& M. C. Neri, eds, 'Programa Bolsa Família: uma década de inclusão e cidadania', Ipea, Brasília.

Osorio, R. G. \& Souza, P. H. G. F. (2012), ‘O programa bolsa família depois do brasil carinhoso: uma análise do potencial de redução da pobreza extrema'. Nota Técnica ${ }^{\circ} 14$.

Ribas, R. P. \& Soares, F. V. (2011), 'Is the effect of conditional transfers on labor supply negligible everywhere?'.

URL: http://www.iza.org/conference_files/worldb2011/ribas_r6802.pdf

Saez, E. (2002), 'Optimal income transfer programs: intensive versus extensive labor supply responses.', The Quarterly Journal of Economics .

Skoufias, E. \& Di Maro, V. (2006), Conditional cash transfers, adult work incentives and poverty. World Bank Policy Research Working Paper 3973.

Souza, P. H. G. F. \& Osorio, R. G.; Soares, S. S. D. (2011), 'Uma metodologia para simular o programa bolsa família'. Texto Para Discussão no 1654.

Teixeira, C. G. (2010), A heterogeneity analysis of the bolsa família programme effect on men and women's work supply. IPC Working Paper, n. 61.

URL: http://www.ipc-undp.org/pub/IPCWorkingPaper61.pdf 


\section{Apêndice A Modelos estimados completos}

Tabela A.1: Regressões completas com as diferentes proxies de informalidade - amostra Carinhoso

\begin{tabular}{|c|c|c|c|c|}
\hline $\begin{array}{l}\text { Variáveis } \\
\text { independentes }\end{array}$ & Conta-própria & $\begin{array}{c}\text { Horas } \\
\text { trabalhadas }\end{array}$ & $\begin{array}{c}\text { Ausência de carteira } \\
\text { de trabalho } \\
\text { assinada }\end{array}$ & $\begin{array}{l}\text { Ausência de } \\
\text { previdência } \\
\text { social }\end{array}$ \\
\hline Carinhoso & $\begin{array}{c}-0,166^{* * *} \\
(0,049)\end{array}$ & $\begin{array}{l}0,386 \\
(1,386)\end{array}$ & $\begin{array}{l}0,003 \\
(0,004)\end{array}$ & $\begin{array}{c}-0,023 \\
(0,171)\end{array}$ \\
\hline Mulher & $\begin{array}{c}-0,021 \\
(0,112)\end{array}$ & $\begin{array}{r}-1,787 \\
(3,188)\end{array}$ & $\begin{array}{c}-0,009 \\
(0,010)\end{array}$ & $\begin{array}{c}-0,028 \\
(0,039)\end{array}$ \\
\hline Negro & $\begin{array}{c}-0,076 \\
(0,062)\end{array}$ & $\begin{array}{c}-0,959 \\
(1,76)\end{array}$ & $\begin{array}{c}-0,002 \\
(0,005)\end{array}$ & $\begin{array}{c}-0,005 \\
(0,022)\end{array}$ \\
\hline Rural & $\begin{array}{c}-0,033 \\
(0,054)\end{array}$ & $\begin{array}{l}0,611 \\
(1,533)\end{array}$ & $\begin{array}{l}0,003 \\
(0,005)\end{array}$ & $\begin{array}{l}0,006 \\
(0,019)\end{array}$ \\
\hline Idade & $\begin{array}{l}0,000 \\
(0,003)\end{array}$ & $\begin{array}{c}-0,025 \\
(0,080)\end{array}$ & $\begin{array}{l}0,000 \\
(0,000)\end{array}$ & $\begin{array}{c}-0,002 \\
(0,001)\end{array}$ \\
\hline Tamanho da família & $\begin{array}{l}0,022 \\
(0,014)\end{array}$ & $\begin{array}{c}-0,005 \\
(0,409)\end{array}$ & $\begin{array}{l}0,000 \\
(0,001)\end{array}$ & $\begin{array}{c}-0,013^{*} \\
(0,005)\end{array}$ \\
\hline Anos de estudo & $\begin{array}{l}0,012 \\
(0,007)\end{array}$ & $\begin{array}{c}-0,489^{*} \\
(0,215)\end{array}$ & $\begin{array}{c}-0,001 \\
(0,001)\end{array}$ & $\begin{array}{l}0,000 \\
(0,003)\end{array}$ \\
\hline $\begin{array}{l}\text { Renda domiciliar per ca- } \\
\text { pita }\end{array}$ & $\begin{array}{l}0,009^{* * *} \\
(0,002)\end{array}$ & $\begin{array}{l}0,031 \\
(0,481)\end{array}$ & $\begin{array}{l}0,000 \\
(0,000)\end{array}$ & $\begin{array}{l}0,001 \\
(0,001)\end{array}$ \\
\hline Filhos no domicílio & $\begin{array}{l}-0,03 \\
(0,026)\end{array}$ & $\begin{array}{c}-0,695 \\
(0,736)\end{array}$ & $\begin{array}{l}0,002 \\
(0,002)\end{array}$ & $\begin{array}{l}0,011 \\
(0,009)\end{array}$ \\
\hline $\begin{array}{l}\text { Horas de trabalho do- } \\
\text { méstico }\end{array}$ & $\begin{array}{c}-0,005^{*} \\
(0,002)\end{array}$ & $\begin{array}{l}-0,207^{* *} \\
(0,073)\end{array}$ & $\begin{array}{l}0,000 \\
(0,000)\end{array}$ & $\begin{array}{l}0,000 \\
(0,001)\end{array}$ \\
\hline Nordeste & $\begin{array}{c}-0,127 \\
(0,073)\end{array}$ & $\begin{array}{l}0,342 \\
(2,087)\end{array}$ & $\begin{array}{c}-0,002 \\
(0,006)\end{array}$ & $\begin{array}{l}0,032 \\
(0,026)\end{array}$ \\
\hline Sudeste & $\begin{array}{l}0,234 \\
(0,145)\end{array}$ & $\begin{array}{r}-5,231 \\
(4,112)\end{array}$ & $\begin{array}{l}0,003 \\
(0,013)\end{array}$ & $\begin{array}{c}-0,042 \\
(0,051)\end{array}$ \\
\hline Sul & $\begin{array}{l}0,039 \\
(0,161)\end{array}$ & $\begin{array}{l}9,876^{*} \\
(4,578)\end{array}$ & $\begin{array}{l}0,001 \\
(0,141)\end{array}$ & $\begin{array}{l}0,032 \\
(0,057)\end{array}$ \\
\hline Centro-Oeste & $\begin{array}{c}-0,4 \\
(0,386)\end{array}$ & $\begin{array}{c}7,185 \\
(10,963)\end{array}$ & $\begin{array}{l}0,004 \\
(0,034)\end{array}$ & $\begin{array}{l}0,062 \\
(0,135)\end{array}$ \\
\hline Constante & $\begin{array}{l}0,118 \\
(0,198)\end{array}$ & $\begin{array}{c}38,491^{* * *} \\
(5,616)\end{array}$ & $\begin{array}{c}1,006^{* * *} \\
(0,017)\end{array}$ & $\begin{array}{c}1,035^{* * * *} \\
(0,069)\end{array}$ \\
\hline$R^{2}$ & 0,194 & 0,158 & 0,015 & 0,07 \\
\hline
\end{tabular}

Nota: Amostra composta por chefes de famílias beneficiárias do Brasil Carinhoso em 2012 e famílias que atenderiam aos critérios de elegibilidade em 2011.

Erro-padrão entre parênteses

${ }^{*} \mathrm{p}<0.05,{ }^{* *} \mathrm{p}<0.01,{ }^{* * *} \mathrm{p}<0.001$ 
Tabela A.2: Regressões completas com variáveis de interação amostra Carinhoso

\begin{tabular}{|c|c|c|c|c|}
\hline & $\begin{array}{l}\text { Interação } \\
\text { mulher e } \\
\text { carinhoso }\end{array}$ & $\begin{array}{l}\text { Interação } \\
\text { negro e } \\
\text { carinhoso }\end{array}$ & $\begin{array}{c}\text { Interação rural } \\
\text { e carinhoso }\end{array}$ & $\begin{array}{l}\text { Interação } \\
\text { regiões e } \\
\text { carinhoso }\end{array}$ \\
\hline Carinhoso & $\begin{array}{c}-0,202^{* * *} \\
(0,060)\end{array}$ & $\begin{array}{c}-0,217 \\
(0,113)\end{array}$ & $\begin{array}{c}-0,171^{*} \\
(0,082)\end{array}$ & $\begin{array}{c}-0,115 \\
(0,111)\end{array}$ \\
\hline Mulher & $\begin{array}{c}-0,064 \\
(0,120)\end{array}$ & $\begin{array}{c}-0,026 \\
(0,113)\end{array}$ & $\begin{array}{l}-0,02 \\
(0,113)\end{array}$ & $\begin{array}{c}-0,094 \\
(0,113)\end{array}$ \\
\hline Mulher*arinhoso & $\begin{array}{l}0,105 \\
(0,102)\end{array}$ & & & \\
\hline Negro & $\begin{array}{c}-0,078 \\
(0,062)\end{array}$ & $\begin{array}{c}-0,103 \\
(0,082)\end{array}$ & $\begin{array}{c}-0,076 \\
(0,062)\end{array}$ & $\begin{array}{c}-0,055 \\
(0,065)\end{array}$ \\
\hline Negro $^{*}$ carinhoso & & $\begin{array}{l}0,063 \\
(0,126)\end{array}$ & & \\
\hline Rural & $\begin{array}{c}-0,031 \\
(0,054)\end{array}$ & $\begin{array}{c}-0,036 \\
(0,054)\end{array}$ & $\begin{array}{c}-0,036 \\
(0,067)\end{array}$ & $\begin{array}{c}-0,017 \\
(0,055)\end{array}$ \\
\hline Rural $^{*}$ carinhoso & & & $\begin{array}{l}0,008 \\
(0,102)\end{array}$ & \\
\hline Idade & $\begin{array}{l}0,000 \\
(0,003)\end{array}$ & $\begin{array}{l}0,000 \\
(0,003)\end{array}$ & $\begin{array}{l}0,000 \\
(0,003)\end{array}$ & $\begin{array}{l}0,000 \\
(0,003)\end{array}$ \\
\hline Tamanho da família & $\begin{array}{l}0,022 \\
(0,014)\end{array}$ & $\begin{array}{l}0,022 \\
(0,014)\end{array}$ & $\begin{array}{l}0,022 \\
(0,014)\end{array}$ & $\begin{array}{l}0,023 \\
(0,014)\end{array}$ \\
\hline Anos de estudo & $\begin{array}{l}0,012 \\
(0,007)\end{array}$ & $\begin{array}{l}0,012 \\
(0,007)\end{array}$ & $\begin{array}{l}0,012 \\
(0,007)\end{array}$ & $\begin{array}{l}0,010 \\
(0,007)\end{array}$ \\
\hline Renda Domiciliar per capita & $\begin{array}{c}0,009^{* * *} \\
(0,002)\end{array}$ & $\begin{array}{c}0,009^{* * *} \\
(0,002)\end{array}$ & $\begin{array}{c}0,009^{* * *} \\
(0,002)\end{array}$ & $\begin{array}{c}0,009^{* * *} \\
(0,002)\end{array}$ \\
\hline Filhos no domicílio & $\begin{array}{c}-0,029 \\
(0,026)\end{array}$ & $\begin{array}{c}-0,029 \\
(0,026)\end{array}$ & $\begin{array}{c}-0,030 \\
(0,026)\end{array}$ & $\begin{array}{c}-0,019 \\
(0,026)\end{array}$ \\
\hline Horas de trabalho doméstico & $\begin{array}{c}-0,005^{*} \\
(0,002)\end{array}$ & $\begin{array}{c}-0,005^{*} \\
(0,002)\end{array}$ & $\begin{array}{c}-0,005^{*} \\
(0,002)\end{array}$ & $\begin{array}{c}-0,003 \\
(0,002)\end{array}$ \\
\hline Nordeste & $\begin{array}{c}-0,125 \\
(0,073)\end{array}$ & $\begin{array}{c}-0,127 \\
(0,074)\end{array}$ & $\begin{array}{c}-0,127 \\
(0,074)\end{array}$ & $\begin{array}{c}-0,080 \\
(0,074)\end{array}$ \\
\hline Nordeste $^{*}$ carinhoso & & & & $\begin{array}{c}-0,047 \\
(0,125)\end{array}$ \\
\hline Sudeste & $\begin{array}{l}0,243 \\
(0,145)\end{array}$ & $\begin{array}{l}0,238 \\
(0,145)\end{array}$ & $\begin{array}{l}0,234 \\
(0,145)\end{array}$ & $\begin{array}{l}0,239 \\
(0,198)\end{array}$ \\
\hline Sudeste $^{*}$ carinhoso & & & & $\begin{array}{l}0,037 \\
(0,314)\end{array}$ \\
\hline Sul & $\begin{array}{l}0,038 \\
(0,161)\end{array}$ & $\begin{array}{l}0,039 \\
(0,161)\end{array}$ & $\begin{array}{l}0,038 \\
(0,162)\end{array}$ & $\begin{array}{l}0,107 \\
(0,196)\end{array}$ \\
\hline Sul $^{*}$ carinhoso & & & & $\begin{array}{c}-0,171 \\
(0,341)\end{array}$ \\
\hline Centro-Oeste & $\begin{array}{c}-0,426 \\
(0,387)\end{array}$ & $\begin{array}{c}-0,401 \\
(0,387)\end{array}$ & $\begin{array}{c}-0,402 \\
(0,388)\end{array}$ & $\begin{array}{c}-0,785 \\
(0,461)\end{array}$ \\
\hline Centro-Oeste ${ }^{*}$ carinhoso & & & & $\begin{array}{l}0,759 \\
(0,662)\end{array}$ \\
\hline Constante & $\begin{array}{l}0,128 \\
(0,198)\end{array}$ & $\begin{array}{l}0,153 \\
(0,210)\end{array}$ & $\begin{array}{l}0,120 \\
(0,200)\end{array}$ & $\begin{array}{l}0,021 \\
(0,200)\end{array}$ \\
\hline$R^{2}$ & 0,196 & 0,195 & 0,194 & 0,173 \\
\hline \multicolumn{5}{|c|}{$\begin{array}{l}\text { Nota: Amostra composta por chefes de famílias beneficiárias do Brasil } \\
\text { Carinhoso em } 2012 \text { e famílias que atenderiam aos critérios de elegibilidade em } \\
2011 . \\
\text { Erro-padrão entre parênteses } \\
{ }^{*} \mathrm{p}<0.05,{ }^{* *} \mathrm{p}<0.01,{ }^{* *} \mathrm{p}<0.001\end{array}$} \\
\hline
\end{tabular}

